\title{
AÇÕES VOLTADAS EM EDUCAÇÃO AMBIENTAL PARA CRIANÇAS DE QUATRO A OITO ANOS EM OFICINAS NO PROJETO RONDON
}

\author{
Samuel de Mello Pinto \\ Universidade de São Paulo \\ samuel.mello@usp.br \\ Márcio Rezende Ribeiro Soares \\ Universidade de São Paulo \\ mrezendesoares@hotmail.com \\ Vanessa Mendes de Queiroz \\ Universidade de São Paulo \\ Vanessa.queiroz@usp.br \\ Nathanael José de Campos \\ Universidade de São Paulo \\ nathanael.campos@ups.br
}

Pietro Pizão Gonzalez

Universidade de São Paulo pietro,gonzalez@usp.br

Rebeca Cristine Ferreira da Silva Universidade de São Paulo rebeca.cristine.silva@usp.br

Diogo Tau Zymberg Tomazewski Universidade de São Paulo diogo.tomaszewski@usp.br

Resumo

Com o objetivo de despertar o interesse das crianças para a temática ambiental, evidenciando a necessidade de preservação das florestas, foram realizadas quatro oficinas durante a Operação Itacaiúnas do Projeto Rondon, no município de Rondon do Pará - PA. As ações ocorreram durante os dias 20 e 30 de Julho de 2015, e tiveram como público-alvo a comunidade mais fragilizada socioeconomicamente. As oficinas nomeadas "O Refúgio", "Boliche da Floresta", "Se lixando" e "Carecacabeludo" apresentaram grande aceitação pelas crianças, sendo interessante notar as diferenças culturais e estruturais da população em relação aos resultados esperados das atividades. No total foram envolvidas mais de 46 crianças tanto na zona urbana quanto rural do município. Pode-se destacar um significativo crescimento pessoal, coletivo e profissional, fruto do impacto sociocultural e do trabalho em conjunto com a população local.

Palavras-chave: Educação ambiental. Projeto Rondon. Educação infantil. Rondon do Pará.

\section{ACTIONS IN ENVIRONMENTAL EDUCATION FOR FOUR-TO-EIGHT-YEAR- OLD CHILDREN IN WORKSHOPS IN THE PROJECT RONDON}

\begin{abstract}
In order to awaken the children's interest for environmental issues, highlighting the need to preserve forests, four workshops were done during the Itacaiúnas Operation of Project Rondon, in the city of Rondon do Pará - PA. The actions occurred between July $20^{\text {th }}$ to July $30^{\text {th }}$ this year, and they had as target audience the most fragile socio-economic community. The workshops were named "O Refúgio", "Boliche da Floresta", "Se lixando" e "Careca-cabeludo" were widely accepted by children, being interesting notice the cultural and structural differences of the population comparing with expected results of activities. Overall, more than 46 children were involved in urban area as well as countryside. It can highlight considerable personal, collective and professional growth, result of sociocultural impact and work together with the community.
\end{abstract}

Keywords: Environmental education. Project Rondon. Preschool. Rondon do Pará. 


\section{ACCIONES DE EDUCACIÓN AMBIENTAL PARA NIÑOS DE CUATRO A OCHO AÑOS DE EDAD EN TALLERES DE PROYECTO RONDON}

\section{Resumen}

Con el fin de despertar el interés de los niños a las cuestiones ambientales, destacando la necesidad de preservar los bosques, se realizaron cuatro talleres durante la Operación Itacaiúnas del Proyecto Rondon, en la ciudad Rondon do Pará PA. Las acciones ocurrieron durante los días 20 y 30 de julio este año, y tuvo como audiencia la comunidad socioeconómica más frágil. Las talleres llamadas "O Refúgio", "Boliche da Floresta", "Se lixando" y "Careca-cabeludo" tuvieron una gran aceptación por los niños, siendo interesante a tener en cuenta las diferencias culturales y estructurales de la población en los resultados esperados de las actividades. En total participaron más de 46 niños, tanto en el municipio urbano y rural. Se puede resaltar un crecimiento personal, colectiva y profesional significativos, resultado del impacto sociocultural y el trabajo en conjunto con la población local.

Palavras clave: Educación ambiental. Proyecto Rondon. Educación infantil. Rondon do Pará. 
Ações voltadas em educação ambiental para crianças de quatro a oito anos em oficinas no Projeto Rondon

\section{INTRODUÇÃO}

A educação ambiental como processo educativo deve ser conduzido a um saber ambiental que se materializa nos valores éticos, políticos e sociais, implicando num sentimento de pertencimento e corresponsabilidade dos diversos segmentos da sociedade para, assim, sermos capazes de entender e superar os problemas ambientais cotidianos (SORRENTINO et. al., 2005). De forma contrária a educação tradicional, essa é uma educação coletiva, na qual seu conteúdo está na realidade socioambiental dos indivíduos ultrapassando os muros da escola (GUIMARÃES, 2007).

À vista disso, o estímulo à percepção ambiental pelas crianças quanto às noções básicas de entendimento, respeito e cuidados com o meio ambiente torna-se fundamental, na mesma medida que a convivência e o respeito entre as pessoas.

Dessa maneira, a extensão universitária como forma de trazer o conhecimento construído na Universidade aliando a realidade da população, pode ser uma das formas de trazer a educação ambiental para a realidade das escolas e estudantes de todo país, resultando em benefícios impares a comunidade local. (BULHÕES et. al, 2010).

O Projeto Rondon, idealizado pelo Ministério da Defesa, é contextualizado nesse sentido, integrando voluntários acadêmicos e comunidades, para que haja a troca de conhecimentos entre as duas partes, contribuindo assim com o desenvolvimento das populações mais carentes do Brasil. Após sua reativação em 2005, o Projeto Rondon realiza operações nos meses de janeiro e julho, viabilizando os estudantes universitários de participar do desenvolvimento local sustentável, com incontáveis aprendizados de vida e cidadania.

Dessa forma, objetivou-se apresentar as atividades realizadas em oficinas de educação ambiental com crianças de quatro a oito anos durante operação do Projeto Rondon. Tais atividades visaram despertar o interesse das crianças para os assuntos relacionados com o meio ambiente e, em especial com as florestas, evidenciando a necessidade de preservação e cuidados com a mesma, demonstrando de maneira lúdica tais conhecimentos.

\section{MATERIAIS E MÉTODOS}

As atividades desenvolveram-se durante a Operação Itacaiúnas do Projeto Rondon em julho de 2015 no município de Rondon do Pará - PA, tendo foco a comunidade mais fragilizada socioeconomicamente. Originado em meados de 1962, e povoada em 1968, o município de 
Ações voltadas em educação ambiental para crianças de quatro a oito anos em oficinas no Projeto Rondon

Rondon do Pará ainda era denominado Candangolândia, e, após a criação do Projeto Rondon, pelo Governo Federal, Candangolândia prosperou e, em 1969, já contando com um posto de gasolina, uma farmácia e um açougue, passando a chamar-se Vila Rondon. Essa denominação, entretanto, perdurou até 1982, quando adquiriu categoria de município com o nome atual de Rondon do Pará.

As ações realizadas no município foram compreendidas no eixo "B", correspondentes à Comunicação, Meio Ambiente, Trabalho, Tecnologia e Produção, e foram planejadas com ênfase na busca de alternativas que possibilitariam auxiliar no desenvolvimento das comunidades de forma viável e sustentável, capacitando a população local para que possam multiplicar e expandir as ações desenvolvidas durante a operação.

No que se refere ao eixo "Meio Ambiente" foram elaboradas três oficinas: "Educação Ambiental com crianças da Educação Infantil", "Controle da Qualidade da Água e Saneamento Básico" e "Arborização Urbana e Paisagismo". Abordando a oficina "Educação Ambiental com crianças", esta foi idealizada com base no projeto "Florestas do Futuro" que é desenvolvido por alunos de graduação do Departamento de Ciências Florestais (LCF) da Escola Superior de Agricultura "Luiz de Queiroz" (ESALQ-USP) em instituições públicas de caridade, ensino e assistência social da região de Piracicaba - SP, desde 2008.

As atividades no município de Rondon do Pará foram executadas no Centro de Referência em Assistência Social, no bairro Jaderlândia, e em três bairros rurais. Com um público variável dependendo da localidade, realizaram-se quatro oficinas em sequência, sendo estas:

1- "O Refúgio": Os participantes tinham que correr em busca de abrigo, em "árvores", fugindo dos imprevistos da floresta. O número de "árvores" (cartazes de copas de árvores no chão) diminuía durante a atividade e, com isso, o grupo tinha o desafio de se abrigar no espaço disponível sem excluir nenhum participante. A oficina tinha como objetivo fornecer a ideia das dificuldades que os animais enfrentam a se abrigarem frente ao desmatamento;

2- "Boliche da Floresta": Consistia na montagem de uma maquete de um paisagem degradada, e elementos como animais e árvores, nos quais os participantes os colocavam na maquete a medida que derrubavam os pinos de boliche, mostrando os componentes de uma floresta e estimulando assim sua preservação, através de perguntas feitas pósconstrução da maquete;

3- "Se Lixando": Trazendo informações referente à redução, reutilização e reciclagem do lixo, os participantes receberam diferentes tipos de resíduos sólidos os quais tinham que ser separados entre aqueles que eram recicláveis daqueles não-recicláveis, de modo que, 
Ações voltadas em educação ambiental para crianças de quatro a oito anos em oficinas no Projeto Rondon

após a separação, os lixos foram conferidos e corrigidos, com breves explicações sobre o destino do lixo e alternativas de reutilização de materiais;

4- "Careca-cabeludo": Consistia na confecção de bonecos elaborados com meias-calças, póde-serra e alpiste, que permitiam que as crianças acompanhassem o desenvolvimento de uma planta, e participassem ativamente desse processo regando-a e tomando os devidos cuidados;

Após realizar as quatro oficinas, as crianças responderam a um "feedback" sobre a oficina que mais apreciaram, desenhando sobre. Em todas as oficinas prezaram-se pela utilização de imagens, maquetes e cores variadas, visto que as crianças se encontram numa faixa etária na qual há grande assimilação de símbolos, imagens mentais e desenhos.

\section{RESULTADOS E ANÁLISES}

As atividades realizaram-se de forma satisfatória apresentando grande aceitação pelas crianças, em especial aquelas com mais dinamismo como o "Boliche da Floresta" e "O Refúgio". Foi interessante notar as diferenças estruturais e culturais da comunidade observada nas atividades, visto que foram planejadas numa realidade diferente da população local. Como exemplo, pode-se citar a oficina "Se lixando" na qual foram trazidos conceitos de reciclagem e a questão da destinação correta do lixo doméstico. Porém, nas zonas rurais não havia coleta de lixo, ao passo que a própria população dava destino aos seus resíduos da forma que fosse possível, aterrando parte destes e incinerando o restante. Com isso, foi necessário, de forma geral, realizar alterações na metodologia das atividades para atender o tema nas adversidades locais.

Observou-se também que muitas das crianças já apresentavam uma bagagem sobre o tema, no que se refere à questão do desmatamento e suas relações com a fauna e cursos hídricos, e sobre a própria questão dos resíduos sólidos, muitos já tinha conhecimento do que era reciclagem e sua importância. Na Ilustração 1 estão demonstrados o "Boliche da Floresta" e "Se lixando". 
Ações voltadas em educação ambiental para crianças de quatro a oito anos em oficinas no Projeto Rondon
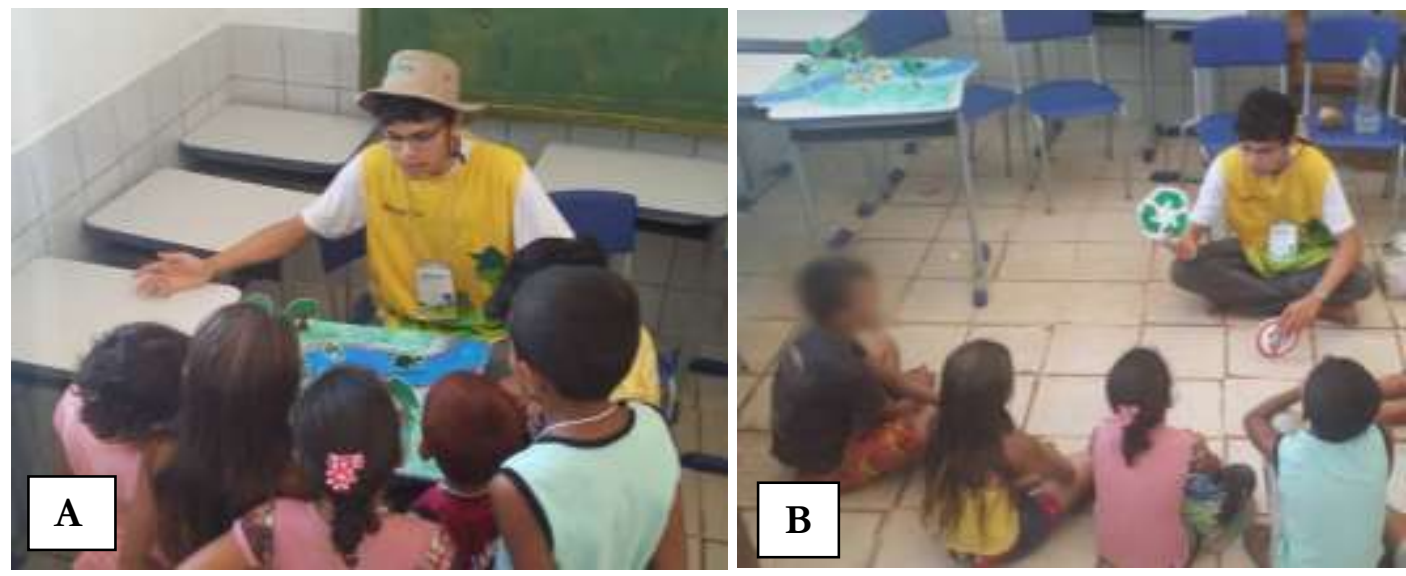

Ilustração 1 - (A) Pós-construção da maquete do "Boliche da Floresta" e explicações sobre. (B) Conversas sobre reciclagem do lixo na oficina "Se lixando".

Fonte: Elaborado pelos autores, 2015.

Como resultado da operação do Projeto Rondon em si, pode-se destacar um significativo crescimento pessoal, coletivo e profissional, fruto do impacto sociocultural e do trabalho em conjunto com a população local. No total foram envolvidas mais de 46 crianças tanto na zona urbana quanto na zona rural do município.

\section{CONSIDERAÇÕES FINAIS}

O Projeto Rondon atualmente se estabelece como um dos grandes projetos extensionistas do país, apresentando resultados positivos para todos os envolvidos. Em relação as atividades realizadas durante a operação em questão, pode-se ressaltar a importância da educação ambiental como um processo contínuo na formação das crianças, pois, apesar das ações do projeto assumirem um caráter pontual, o saber ambiental se solidifica à longo prazo, frente aos diversos problemas ambientais deparados cotidianamente.

\section{REFERÊNCIAS}

BULHÕES, A.E.E.; RAMOS, E.S.; FEIJÓ, E.V.R.S.; SANTOS, L.P.S. Relato de uma experiência de vida: comunidade e rondonistas integrando saberes. Extensio: R. Eletr. de Extensão, Florianópolis, Ano 7, n. 10, p. 158-172, 2010. 
Ações voltadas em educação ambiental para crianças de quatro a oito anos em oficinas no Projeto Rondon

GUIMARÃES, M. Educação ambiental: participação para além dos muros da escola. Vamos cuidar do Brasil : conceitos e práticas em educação ambiental na escola / [Coordenação: Soraia Silva de Mello, Rachel Trajber]. - Brasília: Ministério da Educação, Coordenação Geral de Educação Ambiental: Ministério do Meio Ambiente, Departamento de Educação Ambiental: UNESCO, 2007.

SORRENTINO, M.; MENDONÇA, R.T.P.; JUNIOR, L.A.F. Educação ambiental como política pública. Educação e Pesquisa, São Paulo, v. 31, n. 2, p. 285-299, maio/ago. 2005. 